\title{
Native Arbuscular Mycorrhizal Fungi Characterization from Saline Lands in Arid Oases, Northwest China
}

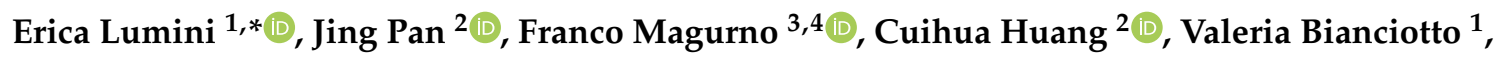 \\ Xian Xue ${ }^{2} \mathbb{D}$, Raffaella Balestrini ${ }^{1}(\mathbb{D})$ and Anna Tedeschi ${ }^{5,+} \mathbb{D}$ \\ 1 National Research Council of Italy, Institute for Sustainable Plant Protection, 10135 Turin, Italy; \\ valeria.bianciotto@ipsp.cnr.it (V.B.); raffaella.balestrini@ipsp.cnr.it (R.B.) \\ 2 Drylands Salinization Research Station, Key Laboratory of Desert and Desertification, Northwest Institute of \\ Eco-Environment and Resources, Chinese Academy of Sciences, 320 West Donggang Road, \\ Lanzhou 730000, China; panjing@lzb.ac.cn (J.P.); hch@lzb.ac.cn (C.H.); xianxue@lzb.ac.cn (X.X.) \\ 3 Department of Botany and Nature Protection, Faculty of Biology and Environmental Protection, \\ University of Silesia in Katowice, Jagiellońska 28, 40-032 Katowice, Poland; franco.magurno@gmail.com \\ 4 Centre of Mountain Environmental Technologies, 43-438 Brenna, Poland \\ 5 National Research Council of Italy, Institute for Agricultural and Forestry Systems in the Mediterranean, \\ 80056 Ercolano, Italy; anna.tedeschi@cnr.it \\ * Correspondence: erica.lumini@ipsp.cnr.it; Tel.: +39-011-6502927 \\ + Current address: Institute of Bioscience and Bioresources, 80055 Portici, Italy.
}

Received: 21 April 2020; Accepted: 4 June 2020; Published: 6 June 2020

\begin{abstract}
Arbuscular mycorrhizal fungi (AMF) colonize land plants in almost every ecosystem, even in extreme conditions, such as saline soils. In the present work, we report the mycorrhizal capacity of rhizosphere soils collected in the dry desert region of the Minqin Oasis, located in the northwest of China (Gansu province), which is characterized by several halophytes. Lycium spp. and Peganum nigellastrum were used as trap plants in a greenhouse experiment to identify autochthonous AMF associated with the halophytes' rhizospheres. Morphological observations showed the typical AMF structures inside roots. Twenty-six molecularly distinct AMF taxa were recovered from soil and root DNA. The taxonomical diversity mirrors the several AMF adapted to extreme environmental conditions, such as the saline soil of central China. Knowledge of the AMF associated with halophytes may contribute to select specific fungal isolates to set up agriculture strategies for protecting non-halophyte crop plants in saline soils.
\end{abstract}

Keywords: arbuscular mycorrhizal fungi (AMF); dry desert region; halophytes; soil biodiversity

\section{Introduction}

Worldwide, soil salinity is a significant threat encountered in all climates. Soils are rendered saline due to the deposition of salt either by natural (primary) or anthropogenic (secondary) processes [1]. Anthropogenic activities, such as poor drainage facilities, irrigation with brackish groundwater, continuous irrigation for long durations, improper management of water, and cultural methods in irrigated agriculture, combined with low rainfall, convert fertile arable land into salt-affected lands, and nearly $7 \%$ of agricultural land area is affected by salinity [2]. The Minqin Oasis, located in the northwest of China (Gansu province), is affected by salinity and desertification due to intense anthropogenic activities, and represents a suitable site for research on the impact of soil salinity. In the Minqin Oasis, $70 \%$ of farmland is affected by aeolian desertification and $85 \%$ is affected by different degrees of salinization, which causes harmful effects on crop production [3]. 
Under salinity conditions, plants show adverse effects in germination, growth, and reproduction that subsequently diminish crop yield [4]. Many modern agricultural crops exhibit a low tolerance to salt, as opposed to wild plants that very often are salt-resistant and can produce significant yields in saline soils. Agricultural production in these salt-affected agricultural environments thus requires the development of salt-tolerant food and fiber crops $[5,6]$. Additionally, besides crop diversification and the identification of plant-tolerant genotypes, one possible strategy towards crop improvement might be to rely on salt-tolerant root-associated soil microorganisms to augment plant performance and growth under stressful environments [7]. Nowadays there is a growing interest in the identification and use of these microorganisms to promote sustainable crop production under abiotic and biotic stresses [8]. Particularly, arbuscular mycorrhizal fungi (AMF) have been already considered as important bio-ameliorators for saline soils [9,10]. Evelin et al. [1] and Begum et al. [11] report several studies in which an enhanced plant growth and tolerance under salinity stress conditions have been observed for different plant species. In detail, AMF can help the plant to cope with salinity stress by enhancing photosynthetic ability and nutrient uptake and increasing antioxidant defense and osmolyte accumulation. AMF colonize land plants in every ecosystem, even in extreme conditions, such as saline soils [12,13]. Although the excess of salinity can negatively affect AMF [14], some AMF are more stress-tolerant than others and they are usually found in stressed and polluted soils $[12,13,15]$. Autochthonous AMF ecotypes are, in fact, already adapted to soils with extreme characteristics [16]. The identification of highly efficient native AMF isolates from these unfavorable environments is expected to improve their exploitation in applicative agricultural programs and provide solutions for farmers to improve plant health and productivity under sub-optimal stressful conditions $[1,12]$.

In the present work, soil samples were collected around the roots of three selected halophytes, i.e., Lycium ruthenicum, L. chinense, and Suaeda salsa, in the dry desert region of the Minqin Oasis located in the northwest of China (Gansu province), and their mycorrhizal potential was evaluated by both morphological and molecular analyses.

\section{Materials and Methods}

\subsection{Study Site and Soil Sampling}

The study was conducted at Minqin Drylands Salinization Research Station of the Key Laboratory of Deserts and Desertification, Northwest Institute of Eco-Environment and Resources belonging to the Chinese Academy of Science (Figure 1). The station, located in Xiquzhen, Gansu province in China $\left(39^{\circ} 02^{\prime} \mathrm{N}, 103^{\circ} 36^{\prime} \mathrm{E}\right)$, was established to study the eco-environment of the area with the purpose of evaluating possible solutions against aridity and salinity. The Minqin Oasis, as well as the salinization research station, has a typical arid continental climate [3,17]. Due to the arid climate, agriculture depends heavily on irrigation. Around the station, several species were able to survive the extreme conditions of soil salinity and water scarcity, such as halophytes i.e., Haloxylon ammodendron, Kalidium foliatum, Suaeda salsa, Nitraria sibirica, Peganum nigellastrum, Reaumuria songarica, Nitraria tangutorum, Tamarix hispida, Tamarix elongata, Lycium ruthenicum, and Lycium chinense (Figure S1). The soil characteristics at a soil depth of $0-20 \mathrm{~cm}$ of the study area are reported in Table S1. In Figure 1, the red dots represent the points of sampling carried out in the area around the research station. Samples were taken at the end of the growing season in 2015 (June, summer) because during this period the plants present their full splendor (with flowers). Soil samples were randomly and carefully taken from the root zone, $20 \mathrm{~cm}$ deep, of three individuals belonging to the selected halophytes: Lycium ruthenicum (S Lr), L. chinense (S Lc), and Suaeda salsa (S Ss) and were homogenized to be considered as a single sample for each plant species (Figure S1). 


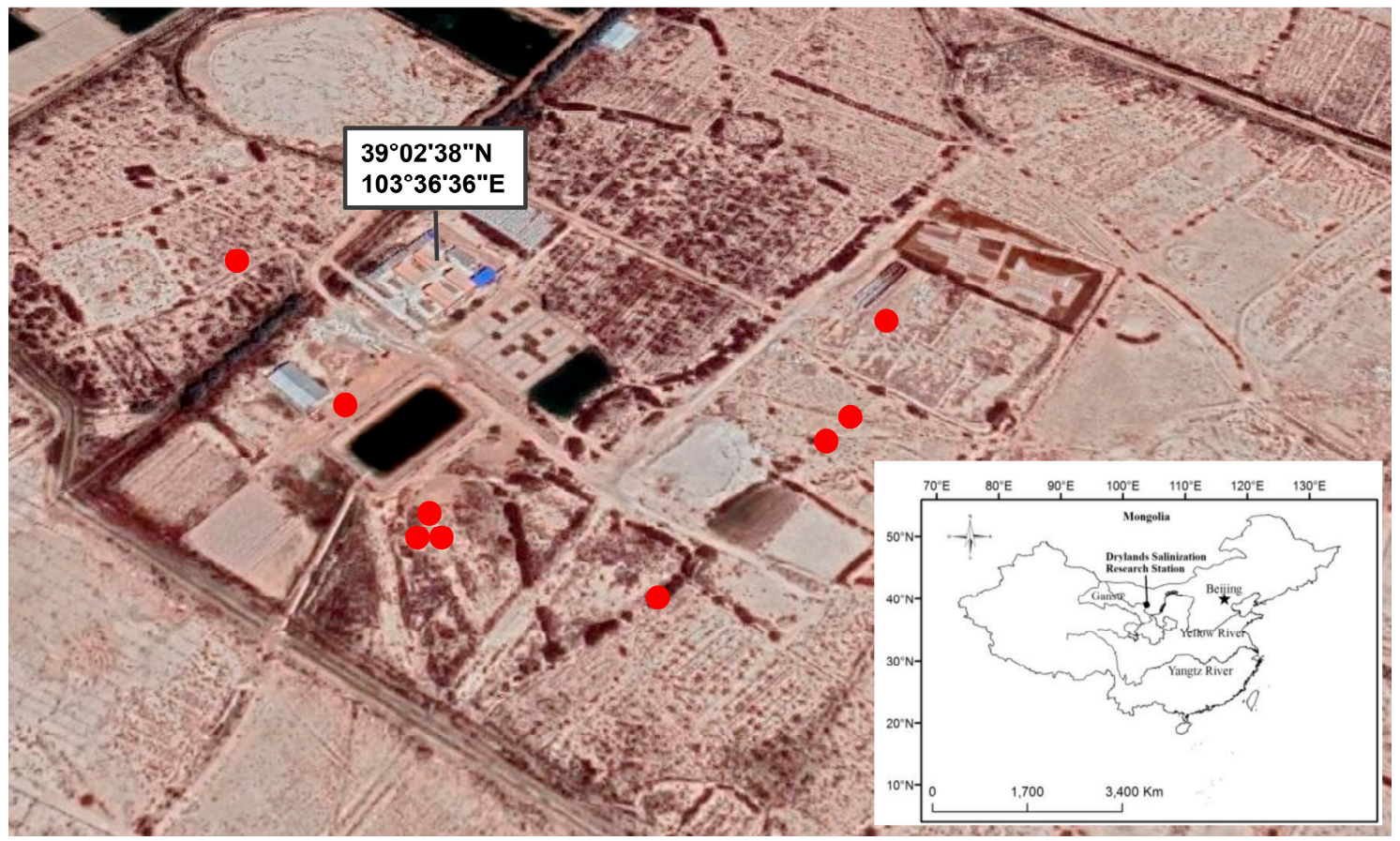

Figure 1. Study area. Red dots represent the sampling points (Landsat imagery, Google Earth).

\subsection{Preparation of Trap Plants and Cultivation}

Soil samples were (i) stored at $-20^{\circ} \mathrm{C}$, for molecular analyses, and (ii) used to set up a greenhouse experiment with three native halophytes: L. ruthenicum $(\mathrm{Lr})$, L. chinense $(\mathrm{Lc})$, and P. nigellastrum (Pn) as trap plants, due their good germination performance (Figure S1). P. nigellastrum was chosen instead of $S$. salsa because of the difficulty of obtaining seedlings of this last species in our growing conditions. In detail, six pots, each with its own pot saucer, were prepared (two for each plant species) using a 50:50 $1 \mathrm{~mm}$ sieved soil:sterilized sand mixture, to facilitate the drainage, and were irrigated with saline nutritional solution (Hoagland $\frac{1}{2}$ ) [18] once a week to mirror the native environmental conditions. Trap plants were grown in a greenhouse, separately from the other plants, inside portable and collapsible plant isolators (i.e., rearing cages).

\subsection{Morphological Analysis for AMF Detection}

After seven months of greenhouse cultivation in pots, Lycium spp. and Peganum sp. roots were harvested, cleaned and, stained with $0.1 \%(w / v)$ cotton blue in $80 \%$ lactic acid overnight, then de-stained three times with lactic acid for $18 \mathrm{~h}$, cut into $1 \mathrm{~cm}$ long segments and placed on microscope slides for morphological observations [18]. Root pieces from the same plants were collected and kept in $-20^{\circ} \mathrm{C}$ for the subsequent molecular analysis. At the same time, the pot substrate (containing soil and sand) were used for spore separation (morphological examination).

\subsection{Root and Soil DNA Extraction, Nested PCR Amplification, Cloning, and RFLP Typing}

To identify the AMF communities associated to the oasis stressed environment we performed a molecular characterization directly on DNA extracted from (1) two replicates of the three soils (S): S Ss (S. salsa), S Lr (L. ruthenicum), and S Lc (L. chinense), and (2) roots ( $R$ ) of L. ruthenicum ( $\mathrm{R} \mathrm{Lr),} \mathrm{L.} \mathrm{chinense}$ ( $\mathrm{R} \mathrm{Lc}$ ), and P. nigellastrum ( $\mathrm{R} \mathrm{Pn}$ ) grown as trap plants in pots.

To overcome the difficulties of mixed starting material, the species composition of AMF in soil and roots were analyzed by a nested PCR approach. The NS1/NS4 universal primers were used in the first amplification, followed by nested amplification with the AMF-specific primers AML1 and AML2 to amplify a fragment of the SSU rDNA (750 bp) [19]. A negative control was included in the 
PCR to check for contamination. All PCR products were checked using 1.5\% agarose gel stained with ethidium bromide (Merck, Darmstadt, Germany). PCR products were then purified using a Wizard ${ }^{\circledR}$ SV Gel and PCR Clean-Up System (Promega Corporation, Madison, WI, USA) cloned into pGEM-T Easy (Promega, Madison, WI, USA) and transformed into Escherichia coli (Xl1 blue). Putative positive transformants were screened in each resulting SSU rRNA gene library, using a second AML1/AML2 amplification following the same PCR conditions described above.

Thirty-two positive clones of the six root clone libraries were tested for restriction fragment length polymorphism (RFLP). RFLP analysis was carried out by independent digestion with HinfI and Hsp92II, according to the manufacturer's instructions (Promega), and analyzed with $2.5 \%$ agarose (in tris-borate-EDTA; TBE) gel electrophoresis. Examples of each RFLP type were chosen for root DNA sequencing, which was performed by Ludwig Maximilians-Universität Munchen (LMU) Sequencing service (Munich, Germany) using the AML2 reverse primer. Sixty-four positive clones for each of the three soil clone libraries were instead sent directly to the LMU sequences service.

\subsection{Phylogenetic Analysis}

Sequences were edited manually with MEGA 6 (Available online: https://www.megasoftware.net/). Non-AMF sequences were discarded after BLASTN analysis. Environmental sequence affiliation was obtained using the evolutionary placement algorithm (EPA) included in RAxML version 8 (Available online: https://github.com/stamatak/standard-RAxML). The sequences obtained in the present work were aligned with 194 reference sequences, selected to represent the main taxonomic groups in the Glomeromycota, and the $18 \mathrm{~S}$ ribosomal RNA sequence of Mortierella polycephala (X89436). Due to the most recent updates in taxonomy and using the 18S-ITS-28S regions or the $28 \mathrm{~S}$ region alone, sequences for several taxa were not available. The alignment was carried out with MAFFT 7 using the "auto" option (Available online: http://mafft.cbrc.jp/alignment/server/). The alignment and a reference tree were provided as input for the RAxML-EPA analysis. For each sequence, the EPA assigns a place in the phylogenetic tree used as backbone (Figure S2). The reference tree used in the RAxML-EPA analysis was built with the 195 sequences mentioned above. Reference sequences were aligned with MAFFT 7 using the "auto" option. To increase the accuracy of the phylogenetic reconstruction, indels coded by FastGap v1.2 (Available online: http://www.aubot.dk/FastGap home.htm) were added to the nucleotide alignment, as described in [20]. A maximum likelihood (ML) phylogenetic inference of the partitioned alignment was computed through the CIPRES web portal [21] with RAxML ver. 8.2.12 [22], choosing GTRGAMMA as a substitution model and 1000 iterations for rapid bootstrapping. A Mortierella polycephala sequence (X89436) was used to root the tree. Sequences representative for each phylogenetic node were deposited in the NCBI database (MN597010- MN597041).

\section{Results and Discussion}

Despite the low mycorrhizal affinity of the halophytes that has been reported [23], the evaluation of root colonization allowed the verification of the presence of typical AMF structures (arbuscules, hyphae, and vesicles) inside the roots of the considered trap plants, i.e., two Lycium species and P. nigellastrum (Figure 2 for L. ruthenicum and not shown for the other two plant species). These results suggested the presence of AMF propagules in the original collected soils and their germination capability and infection. This statement has also been confirmed by spore extraction and microscopical observations, showing the presence of spores with different morphologies typical of different AMF taxa (Figure 2).

The density of AMF spores in desert saline areas has been controversially reported, i.e., very low, with a general inhibition of germination and AMF hyphal growth [24], or not significantly decreased with a relatively high spore number (mean of 100 per $10 \mathrm{~g}$ soil) [25]. This fact has been partially explained by AMF low root colonization levels that might conversely stimulate spore production under severe saline conditions [26]. As reported by Antunes et al. [27], different AMF behaviors might result from adaptations towards environmental conditions, prevailing at their place of origin, and by differences in AMF structural traits. Such well-adapted AMF ecotypes may then have unique 
physiological capabilities to cope with the extreme conditions prevailing in the desert, such as long drought seasons leading to desiccation, and high salt concentration.
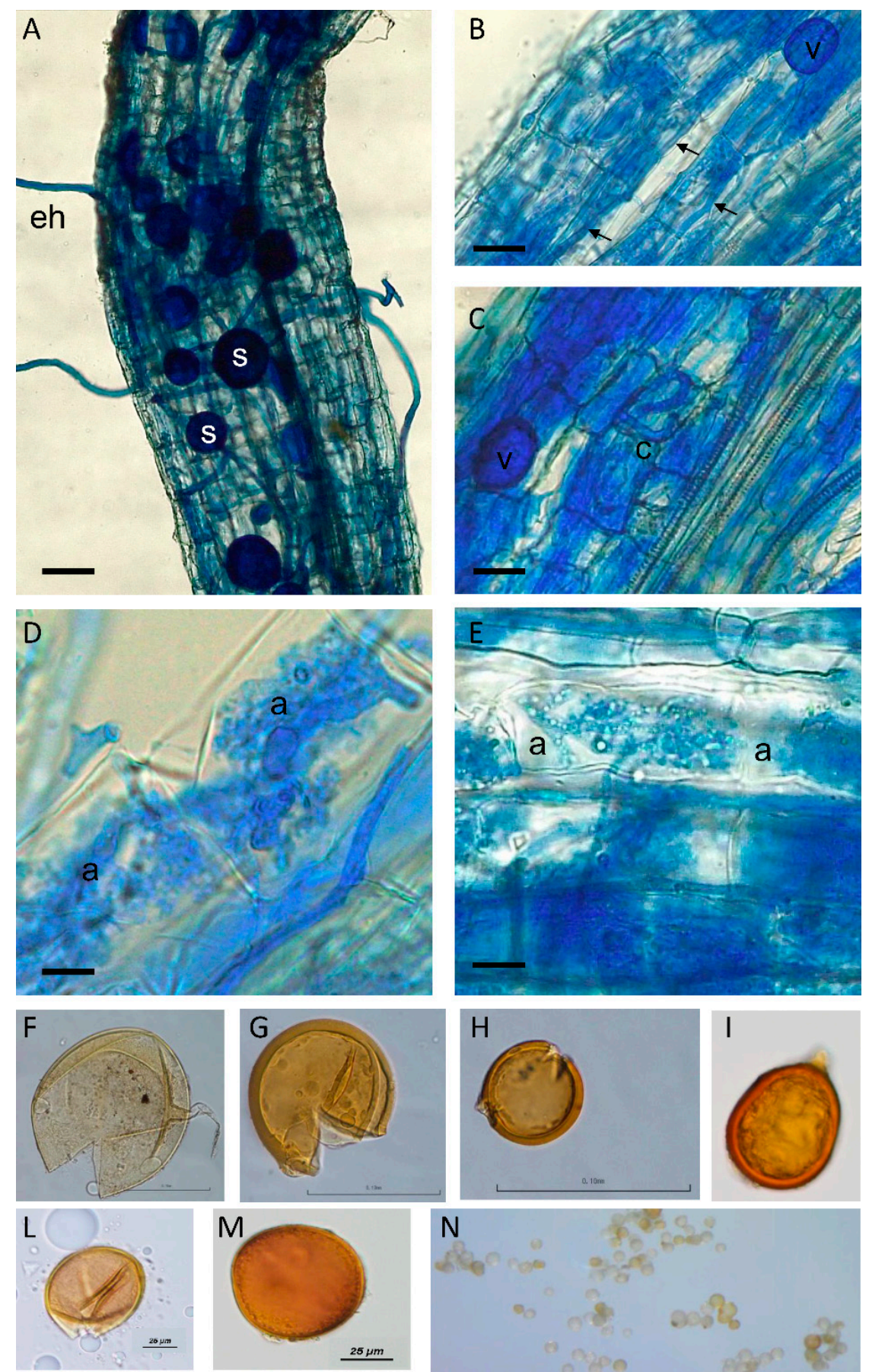

Figure 2. Arbuscular Mycorrhizal Fungal (AMF) colonized Lycium ruthenicum roots after staining with cotton blue to highlight several fungal structures. (A) External hyphae (eh) and spores (s) are evident around the root. Bar $=200 \mu \mathrm{m}$. (B) At a higher magnification, intercellular hyphae are evident (arrows). A vesicle ( $\mathrm{v}$, a storage structure) is also evident. Bar $=150 \mu \mathrm{m}$. (C) A coil (c) is present inside a cortical cell, as well as a vesicle (v). Bar $=115 \mu \mathrm{m}$. (D,E) Magnification of cortical cells containing arbuscules (a), which are considered the key symbiosis structures where nutritional exchanges occur. Bars $=50$ and $30 \mu \mathrm{m}$, respectively. (F-N) Spores of different AMF morphotypes, mirrored by the different spore morphology, isolated from the soil of trap plants. 
Trap plants have been previously used by Ferrol and colleagues [28] to bait the whole population of native AMF, since AMF spores in soil samples taken directly from the ecosystem of Pistacea lentiscus, one of the most representative shrub species from Mediterranean regions and a target plant for revegetation programs, was relatively low, and the only AMF species recognized in the native soil was Paraglomus occultum. In our work, the DNA extracted from trap plant roots, as well as from soils, was successfully amplified using the nested PCR approach, obtaining a fragment of the expected size (ca. $750 \mathrm{bp}$ ). Overall, 288 clones from roots and soils were sent for sequencing and 199 (60 from root samples and 139 from soils) were available for phylogenetic analysis (Table 1; Figure S3). Phylogenetic analyses revealed AMF belonging to two out of four orders of the phylum Glomeromycota: sequences were distributed over four families (Glomeraceae, Claroideoglomeraceae, Diversisporaceae, and Gigasporaceae) and different clades. In total, 26 AMF taxa were retrieved: nine AMF taxa from rhizosphere soils of L. ruthenicum, L. chinense, and Suaeda salsa (Gi1, Sept2, Glo4, Do1, Do2, Rh1, Rh2, Glo6, Glo7) and 17 AMF taxa from roots of L. ruthenicum (Lr), L. chinense (Lc), and Peganum nigellastrum (Pn) (Div1, Div2, Div3, Div4, Cla1, Cla2, Cla3, Cla4, Cla5, Fun1, Fun2, Fun3, Sept2, Glo1, Glo2,Glo3, Glo5) (Table 1). The most abundant genera retrieved from roots were represented by Diversispora accounting for $38.6 \%$ of the total clones analyzed by RFLPs, followed by Claroidoglomus, and Glomus, representing $27.2 \%$ and $24.4 \%$, respectively. The less abundant taxa retrieved from roots were those belonging to Funneliformis (2.8\%) and Septoglomus genera, accounting for $2.8 \%$ and $2.7 \%$ of the total clones, respectively.

Table 1. Phylotypes of arbuscular mycorrhizal fungi, identified using the AML1-AML2 primer pair, in rhizosphere soils of L. ruthenicum, L. chinense, and S. salsa and in roots of the trap plant species $L$. ruthenicum, L. chinense, and P. nigellastrum.

\begin{tabular}{|c|c|c|c|c|c|}
\hline \multirow[t]{2}{*}{ Reference AMF } & \multirow[t]{2}{*}{ Node } & \multirow[t]{2}{*}{ Confidence Values } & \multirow[t]{2}{*}{ Phylogroups } & \multicolumn{2}{|c|}{$\mathbf{N}^{\circ}$ of Clones Sequenced } \\
\hline & & & & Soil & Root \\
\hline Gigaspora margarita & I111 & 1.00 & Gi1 & 24 & 0 \\
\hline Diversispora spurca & I182 & 0.80 & Div1 & 0 & 1 \\
\hline Diversispora spurca & $\mathrm{I} 183$ & 0.83 & Div2 & 0 & 7 \\
\hline Diversispora sp. & I206 & 0.74 & Div3 & 0 & 1 \\
\hline Diversisporaceae sp. & $\mathrm{I} 222$ & 0.95 & Div4 & 0 & 15 \\
\hline Claroideoglomus sp. & $\mathrm{I} 236$ & 1 & Cla1 & 1 & 1 \\
\hline Claroideoglomus sp. & $\mathrm{I} 240$ & 0.95 & Cla2 & 0 & 1 \\
\hline Claroideoglomus sp. & $\mathrm{I} 239$ & 0.36 & Cla3 & 0 & 6 \\
\hline Claroideoglomus sp. & $\mathrm{I} 267$ & 0.35 & Cla4 & 0 & 2 \\
\hline Claroideoglomus sp. & $\mathrm{I} 268$ & 0.83 & Cla5 & 0 & 3 \\
\hline Funneliformis sp. & $\mathrm{I} 281$ & 0.82 & Fun1 & 0 & 1 \\
\hline Funneliformis mosseae & $\mathrm{I} 287$ & 0.95 & Fun2 & 0 & 1 \\
\hline Funneliformis sp. & $\mathrm{I} 291$ & 0.78 & Fun3 & 0 & 2 \\
\hline Septoglomus sp. & I304 & 0.90 & Sept1 & 1 & 0 \\
\hline Septoglomus sp. & I297 & 1.00 & Sept2 & 26 & 3 \\
\hline Glomeraceae sp. & I312 & 1.00 & Glo1 & 2 & 2 \\
\hline Dominikia iranica & I321 & 0.68 & Do1 & 1 & 0 \\
\hline Glomeraceae sp. & I322 & 1.00 & Glo2 & 3 & 4 \\
\hline Glomeraceae sp. & I326 & 0.93 & Glo3 & 8 & 3 \\
\hline Glomeraceae sp. & I327 & 0.95 & Glo4 & 5 & 0 \\
\hline Dominikia indica & I339 & 1.00 & Do2 & 1 & 0 \\
\hline Glomeraceae sp. & $\mathrm{I} 340$ & 1.00 & Glo5 & 11 & 7 \\
\hline Rhizophagus intraradices & I351 & 0.80 & Rh1 & 1 & 0 \\
\hline Rhizophagus arabicus & $\mathrm{I} 373$ & 0.89 & Rh2 & 28 & 0 \\
\hline Glomeraceae sp. & I380 & 0.85 & Glo6 & 26 & 0 \\
\hline Glomeraceae sp. & I383 & 1 & Glo7 & 1 & 0 \\
\hline Total & & & 26 & 139 & 60 \\
\hline
\end{tabular}


Despite the AMF primer specificity, $4.3 \%$ of the total clones were referred to as contaminants (plants, other fungi), as already reported in literature [29]. Each trap plant species captured a different plethora of AMF taxa. In the roots of L. ruthenicum ( $\mathrm{Lr}$ ), the most abundant taxa were those ascribed to Claroidoglomus and Diversispora, while on the contrary, L. chinense (Lc) was mainly colonized by many different taxa affiliated to Glomeraceae (i.e., Glomus and Funneliformis spp.), while in the roots of P. nigellastrum (Pn), AMF belonging to different Diversispora phylogroups and, to a lesser extent, Claroidoglomus and Septoglomus taxa were retrieved. From soil-based sequencing, most sequences were ascribed to Glomeraceae and, in particular, to taxa included in the basal Rhizophagus-Sclerocystis-Ohelia groups (26.6\%), followed by Rhizophagus/Rhizoglomus taxa (i.e., Rh. intraradices, Rh. arabicus), representing 20.8\%, Septoglomus (19.4\%), and taxa belonging to Dominikia and Dominikia-related phylogroups (14.3\%). In addition, $17.2 \%$ of sequences were assigned to Gigasporaceae (Gi. margarita) and only $0.7 \%$ to Claroidoglomus.

Our results reveal that the AMF communities identified were only partially shared by the three plant species studied, as expected. Each trap plant species captured a different plethora of AMF taxa, suggesting that the vegetation in the considered stressed area, including Chenopodiaceae spp. (often described as not mycorrhizal plants), retains potential rhizospheric communities, offering a natural wealth of AMF and probably other root-associated microorganisms (e.g., plant growth-promoting bacteria), as reported in different ecosystems. These results are intriguing and confirmed previous studies where rhizospheric soil from Chenopodiaceae plant species, such as Sueda spp., maintained AMF potential at the same levels of other mycorrhizal plant host species in saline-stressed semi-desert and desert environments [26,30]. Both soil-based and plant root sequencing showed AMF taxa corresponded to isolates already reported in similar stressed environments, either in China [31,32] or the Mediterranean basin, where many ecosystems are subjected to desertification and a rapid increase in soil salinity $[13,28,33]$. In detail, our findings confirmed AMF species belonging to Glomerales, such as Rh. intraradices, Fu. mosseae, $\mathrm{Fu}$. geosporus, $\mathrm{Cl}$. etunicatum, $\mathrm{Cl}$. claroideum, Se. constrictum, as the most frequently retrieved taxa in saline and drought environments ([16] and references therein). The presence of species belonging to the Gigaspora genus was also previously found in ecosystems without anthropogenic disturbances [34].

Overall, our results provide new information useful for the optimization of AMF application to sustain agriculture in saline environments, promoting the selection and the use of AMF associated with native plants. Native AMF consortia, consisting of several taxa already adapted to extreme conditions and with different symbiotic behaviors, can, in fact, be more efficient at preserving these ecosystems from advancing desertification and secondary soil salinization due to irrigation. More specifically, AMF can mitigate the vulnerability of horticultural crops to water scarcity and soil salinity, thus allowing viable cultivation in extreme environments. Moreover, digging into the functional diversity of autochthonous AMF ecotypes for their impact on plant tolerance to environmental stresses, will promote a most effective use of these beneficial soil microorganisms in sustainable agriculture programs in a climate change scenario.

Supplementary Materials: Supplementary materials can be found at http://www.mdpi.com/2309-608X/6/2/80/s1. Figure S1: Halophytic species present in the study area: (A) Haloxylon ammodendron, (B) Kalidium foliatum, (C) Lycium chinense, (D) Lycium ruthenicum, (E) Nitraria sibirica, (F) Nitraria tangutorum, (G) Peganum nigellastrum, (H) Reaumuria songarica, (I) Suaeda salsa, (J) Tamarix elongata, and (K) Tamarix hispida. Figure S2: Phylogenetic backbone tree. A $50 \%$ majority rule consensus phylogram produced from a maximum likelihood analysis of 194 partial SSU rDNA reference sequences, selected to represent the main taxonomic groups in the Glomeromycota. A sequence of Mortierella polycephala (X89436) was added as an outgroup. The reference tree served as base for the one-by-one insertion, and therefore affiliation, of the query sequences. Figure S3: Node tree. Position of the nodes on the reference tree after the EPA analysis. The tree is shown as a cladogram to ease the visualization of the nodes, highlighted in yellow, where the query sequences were placed.

Author Contributions: Conceptualization, E.L., X.X., R.B., and A.T.; methodology, E.L., R.B., and A.T.; formal analysis, F.M.; investigation, E.L., J.P., C.H., V.B., R.B., and A.T.; resources, X.X. and A.T.; writing-original draft preparation, E.L. and A.T.; writing-review and editing, E.L., R.B., and A.T. All authors have read and agreed to the published version of the manuscript. 
Funding: Collaborative research by the authors was supported by the National Research Council and by the Chinese Academy of Science under their bilateral cooperation agreement for the periods 2014-2016 and by the National Key Research and Development Program of China (No. 2017YFE0119100).

Acknowledgments: The co-author Anna Tedeschi is grateful to Giorgio Matteucci, for the partial funding of field and laboratory experiments. The technical support of Emile Cavalet-Giorsa for the molecular analysis is also gratefully acknowledged.

Conflicts of Interest: The authors declare no conflict of interest. The funders had no role in the design of the study; in the collection, analyses, or interpretation of data; in the writing of the manuscript, or in the decision to publish the results.

\section{References}

1. Evelin, H.; Devi, T.S.; Gupta, S.; Kapoor, R. Mitigation of salinity stress in plants by arbuscular mycorrhizal symbiosis: Current understanding and new challenges. Front. Plant Sci. 2019, 10, 470. [CrossRef] [PubMed]

2. Hashem, A.; Alqarawi, A.A.; Radhakrishnan, R.; Al-Arjani, A.F.; Aldehaish, H.A.; Egamberdieva, D.; Abd Allah, E.F. Arbuscular mycorrhizal fungi regulate the oxidative system, hormones and ionic equilibrium to trigger salt stress tolerance in Cucumis sativus L. Saud. J. Biol. Sci. 2018, 25, 1102-1114. [CrossRef] [PubMed]

3. Tedeschi, A.; Zong, L.; Huang, C.H.; Vitale, L.; Volpe, M.G.; Xue, X. Effect of salinity on growth parameters, soil water potential and ion composition in Cucumis melo cv. Huanghemi in North-Western China. J. Agric. Crop Sci. 2017, 203, 41-55. [CrossRef]

4. Chinnusamy, V.; Jagendorf, A.; Zhu, J.-K. Understanding and improving salt tolerance in plants. Crop Sci. 2005, 45, 437-448. [CrossRef]

5. Rozema, J.; Flowers, T. Crops for a salinized world. Science 2008, 322, 1478-1480. [CrossRef] [PubMed]

6. Joshi, R.; Ramanarao, M.V.; Bedre, R.; Sanchez, L.; Pilcher, W.; Zandkarimi, H.; Baisakh, N. Salt adaptation mechanisms of halophytes: Improvement of salt tolerance in crop plants. In Elucidation of Abiotic Stress Signaling in Plants: Functional Genomics Perspectives; Pandey, G.K., Ed.; Springer: New York, NY, USA, 2015; Volume 2, pp. 243-280.

7. Dodd, I.C.; Perez-Alfocea, F. Microbial amelioration of crop salinity stress. J. Exp. Bot. 2012, 63, 3415-3428. [CrossRef] [PubMed]

8. Balestrini, R.; Lumini, E. Focus on mycorrhizal symbioses. Appl. Soil Ecol. 2018, 123, 299-304. [CrossRef]

9. Etesami, H.; Beattie, G.A. Mining halophytes for plant growth-promoting halotolerant bacteria to enhance the salinity tolerance of non-halophytic crops. Front. Microbiol. 2018, 9, 148. [CrossRef]

10. Navarro, J.M.; Pérez-Tornero, O.; Morte, A. Alleviation of salt stress in citrus seedlings inoculated with arbuscular mycorrhizal fungi depends on the rootstock salt tolerance. J. Plant Physiol. 2014, 171, 76-85. [CrossRef]

11. Begum, N.; Qin, C.; Ahanger, M.A.; Raza, S.; Khan, M.I.; Ashraf, M.; Ahmed, N.; Zhang, L. Role of arbuscular mycorrhizal fungi in plant growth regulation: Implications in abiotic stress tolerance. Front. Plant Sci. 2019, 10, 1068. [CrossRef]

12. Estrada, B.; Aroca, R.; Barea, J.M.; Ruiz-Lozano, J.M. Native arbuscular mycorrhizal fungi isolated from a saline habitat improved maize antioxidant systems and plant tolerance to salinity. Plant Sci. 2013, 201, 42-51. [CrossRef] [PubMed]

13. Estrada, B.; Beltrán-Hermoso, M.; Palenzuela, J.; Iwase, K.; Ruiz-Lozano, J.M.; Barea, J.M.; Oehl, F. Diversity of arbuscular mycorrhizal fungi in the rhizosphere of Asteriscus maritimus Less., a representative plant species in arid and saline Mediterranean ecosystems. J. Arid Environ. 2013, 97, 170-175. [CrossRef]

14. Juniper, S.; Abbott, L.K. Soil salinity delays germination and limits growth of hyphae from propagules of arbuscular mycorrhizal fungi. Mycorrhiza 2006, 16, 371-379. [CrossRef] [PubMed]

15. Armada, E.; Azcón, R.; López-Castillo, O.M.; Calvo-Polanco, M.; Ruiz-Lozano, J.M. Autochthonous arbuscular mycorrhizal fungi and Bacillus thuringiensis from a degraded Mediterranean area can be used to improve physiological traits and performance of a plant of agronomic interest under drought conditions. Plant Physiol. Biochem. 2015, 90, 64-74. [CrossRef]

16. Lenoir, I.; Fontaine, J.; Sahraoui, A.L.H. Arbuscular mycorrhizal fungal responses to abiotic stresses: A review. Phytochemistry 2016, 123, 4-15. [CrossRef]

17. Xue, X.; Liao, J.; Hsing, Y.T.; Huang, C.H.; Liu, F.M. Policies, land use, and water resource management in an arid oasis ecosystem. Environ. Manag. 2015, 55, 1036-1051. [CrossRef] 
18. Pollastri, S.; Savvides, A.; Pesando, M.; Lumini, E.; Volpe, M.G.; Ozudogru, E.A.; Faccio, A.; De Cunzo, F.; Michelozzi, M.; Lambardi, M.; et al. Impact of two arbuscular mycorrhizal fungi on Arundo donax L. response to salt stress. Planta 2018, 247, 573-585. [CrossRef]

19. Borriello, R.; Berruti, A.; Lumini, E.; Della Beffa, M.T.; Scariot, V.; Bianciotto, V. Edaphic factors trigger diverse AM fungal communities associated to exotic camellias in closely located Lake Maggiore (Italy) sites. Mycorrhiza 2015, 25, 253-265. [CrossRef]

20. Błaszkowski, J.; Chwat, G.; Góralska, A.; Ryszka, P.; Orfanoudakis, M. Septoglomus jasnowskae and Septoglomus turnauae, two new species of arbuscular mycorrhizal fungi (Glomeromycota). Mycol. Prog. 2014, 13, 999-1009. [CrossRef]

21. Miller, M.A.; Pfeiffer, W.; Schwartz, T. Creating the CIPRES Science Gateway for inference of large phylogenetic trees. In Proceedings of the Gateway Computing Environments Workshop (GCE); IEEE Publisher: New Orleans, LA, USA, 2010; pp. 1-8.

22. Stamatakis, A. RAxML version 8: A tool for phylogenetic analysis and post-analysis of large phylogenies. Bioinformatics 2014, 30, 1312-1313. [CrossRef]

23. Brundrett, M.C. Mycorrhizas in natural ecosystems. In Advances in Ecological Research; Macfayden, A., Begon, M., Fitter, A.H., Eds.; Academic Press: London, UK, 1991; Volume 21, pp. 171-313.

24. Carvalho, L.M.; Correia, P.H.; Martins-Loucao, A. Arbuscular mycorrhizal fungal propagules in a salt marsh. Mycorrhiza 2001, 14, 165-170. [CrossRef] [PubMed]

25. Aliasgharzadeh, N.; Saleh Rastin, N.; Towfighi, H.; Alizadeh, A. Occurrence of arbuscular mycorrhizal fungi in saline soils of the Tabriz Plain of Iran in relation to some physical and chemical properties of soil. Mycorrhiza 2001, 11, 119-122. [CrossRef] [PubMed]

26. Becerra, A.; Bartoloni, N.; Cofré, N.; Soteras, F.; Cabello, M. Arbuscular mycorrhizal fungi in saline soils: Vertical distribution at different soil depth. Braz. J. Microbiol. 2014, 45, 585-594. [CrossRef] [PubMed]

27. Antunes, P.M.; Koch, A.M.; Morton, J.B.; Rillig, M.C.; Klironomos, J.N. Evidence for functional divergence in arbuscular mycorrhizal fungi from contrasting climatic origins. New Phytol. 2011, 189, 507-514. [CrossRef]

28. Ferrol, N.; Calvente, R.; Cano, C.; Barea, J.-M.; Azcón-Aguilar, C. Analysing arbuscular mycorrhizal fungal diversity in shrub-associated resource islands from a desertification-threatened semiarid Mediterranean ecosystem. Appl. Soil Ecol. 2004, 25, 123-133. [CrossRef]

29. Berruti, A.; Borriello, R.; Lumini, E.; Scariot, V.; Bianciotto, V.; Balestrini, R. Application of laser microdissection to identify the mycorrhizal fungi that establish arbuscules inside root cells. Front. Plant Sci. 2013, 4, 135. [CrossRef]

30. Zhao, Y.; Yu, H.; Zhang, T.; Guo, J. Mycorrhizal colonization of chenopods and its influencing factors in different saline habitats. China J. Arid Land 2017, 9, 143-152. [CrossRef]

31. Goomaral, A.; Iwase, K.; Undarmaa, J.; Matsumoto, T.; Yamato, M. Communities of arbuscular mycorrhizal fungi in Stipa krylovii (Poaceae) in the Mongolian steppe. Mycoscience 2013, 54, 122-129. [CrossRef]

32. Guo, X.; Gong, J. Differential effects of abiotic factors and host plant traits on diversity and community composition of root-colonizing arbuscular mycorrhizal fungi in a salt-stressed ecosystem. Mycorrhiza 2014, 24, 79-94. [CrossRef]

33. Torrecillas, E.; Torres, P.; Alguacil, M.M.; Querejeta, J.I.; Roldan, A. Influence of habitat and climate variables on arbuscular mycorrhizal fungus community distribution, as revealed by a case study of facultative plant epiphytism under semiarid conditions. J. Appl. Environ. Microbiol. 2013, 79, 7203-7209. [CrossRef]

34. Rodriguez-Echevarria, S.; Freitas, H. Diversity of AMF associated with Ammophila arenaria ssp arundinacea in Portuguese sand dunes. Mycorrhiza 2006, 16, 543-552. [CrossRef] [PubMed]

(C) 2020 by the authors. Licensee MDPI, Basel, Switzerland. This article is an open access article distributed under the terms and conditions of the Creative Commons Attribution (CC BY) license (http://creativecommons.org/licenses/by/4.0/). 